Rapport - Société canadienne d'histoire de l'Église catholique

\title{
Discours de Mgr G.-H. Dufour, p.d., représentant de Son Exc. Mgr Marius Paré
}

\section{Georges-H. Dufour}

Volume 32, 1965

URI : https://id.erudit.org/iderudit/1007333ar

DOI : https://doi.org/10.7202/1007333ar

Aller au sommaire du numéro

Éditeur(s)

Les Éditions Historia Ecclesiæ Catholicæ Canadensis Inc.

ISSN

0318-6148 (imprimé)

1927-7075 (numérique)

Découvrir la revue

Citer ce document

Dufour, G.-H. (1965). Discours de Mgr G.-H. Dufour, p.d., représentant de Son Exc. Mgr Marius Paré. Rapport - Société canadienne d'histoire de l'Église catholique, 32, 75-76. https://doi.org/10.7202/1007333ar

Tous droits réservés @ Ces Éditions Historia Ecclesiæ Catholicæ Canadensis Inc., 1966
Ce document est protégé par la loi sur le droit d'auteur. L'utilisation des services d'Érudit (y compris la reproduction) est assujettie à sa politique d'utilisation que vous pouvez consulter en ligne.

https://apropos.erudit.org/fr/usagers/politique-dutilisation/ 


\title{
Discours de Mgr G.-H. Dufour, p.d. représentant de Son Exc. Mgr Marius Paré
}

\author{
M. le Sous-Ministre, \\ Mgr le Président général de la Société, \\ Chers amis,
}

Il me semble que Son Excellence Mgr Paré eût été particulièrement heureux de se trouver parmi vous ce soir; non seulement parce que l'Evêque du diocèse se doit d'encourager toute noble entreprise, tout ce qui est beau et bien, mais parce que j'ai cru découvrir en lui une compétence particulière en Histoire — n'a-t-il pas été professeur d'Histoire ? - et un amour fervent de l'Eglise. Mais hélas ! il a dû se faire remplacer. Si je suis sûr de ne pas faire écran à Son Excellence parce qu'il n'y a rien en moi qui puisse retenir votre attention, il n'est pas aussi sûr que son message ne soit pas déformé en passant par ma bouche. Mais j'essaierai de traduire fidèlement sa pensée telle que j'ai pu la connaître depuis que nous avons le privilège d'avoir Son Excellence parmi nous.

C'est une joie et un honneur pour notre diocèse d'accueillir le Congrès annuel de la Société Canadienne d'Histoire de l'Eglise Catholique. D'où nous vient cet honneur ? Unde hoc mihi ? Est-ce dû à la présence à votre tête de Mgr Victor Tremblay, cet infatigable travailleur, cet entraîneur irrésistible? Ou l'avez-vous mis à votre tête en prévision d'un congrès à Chicoutimi ? Peu importe! Causae sunt ad invicem causce, les causes exercent entre elles une causalité réciproque.

Quoi qu'il en soit, soyez remerciés d'avoir bien voulu tenir vos assises à Chicoutimi et d'avoir choisi, parmi vos sujets d'étude, des personnages ou des œuvres qui nous intéressent particulièrement.

Félicitations spéciales aux conférenciers de ce soir qui ont bien mis en relief des hommes qui font honneur à notre histoire.

Mesdames et Messieurs, vous étudiez l'Histoire de l'Eglise; vous suivez l'Israel de Dieu, sorti d'Egypte, en marche, à travers le désert, vers la Terre promise; vos activités, vos travaux sont dignes d'éloge et d'admiration, propres à élever les esprits et les cours, et s'inscrivent bien dans les préoccupations de la pensée catholique à l'heure actuelle.

Car, c'est l'heure de l'Eglise! L'événement majeur de notre siècle, le deuxième Concile du Vatican, veut être le Concile de l'Eglise; la Constitution dogmatique sur l'Eglise en sera la pièce principale.

Le Pontife qui préside aujourd'hui à la marche de l'Eglise, a une dévotion exceptionnelle à l'Eglise; et cela depuis longtemps. Alors que 
Mgr Montini était aumônier des étudiants universitaires italiens, Mgr Pignedoli, notre Délégué Apostolique actuel, écrivait de lui en 1954: - Mgr Montini parle tout le temps de l'Eglise. C'est son sujet préféré et c'est tout naturel. Mais la façon dont il en parle n'a rien de banal. Il y met la chaleur et l'émerveillement d'un converti d'hier. *

Il n'est donc pas surprenant que la première encyclique de Paul VI se soit intitulée Ecclesiam Suam, et que ce soit une réflexion de l'Eglise sur elle-même, sur les voies par lesquelles elle doit exercer sa mission à l'heure présẹtente.

Et vous aussi, Mesdames et Messieurs, vous aimez l'Eglise et vous vous penchez sur son mystère, non pas précisément pour essayer d'en donner directement quelque connaissance abstraite ou pour le contempler dans ses définitions dogmatiques, mais pour le suivre sur les routes de l'histoire, pour le saisir quelque peu à travers les hommes et les œuvres inspirés par lui et ordonnés à sa croissance, à son développement dans le monde.

Vous enrichissez ainsi le domaine de l'Histoire, le domaine de la culture profane et vous suivez le dessein de Dieu à travers les vicissitudes des temps.

C'est une œuvre belle et digne d'encouragement. Que votre Société veuille bien accepter, avec nos félicitations, nos vœux de succès et d'heureuse persévérance dans un si digne labeur. 